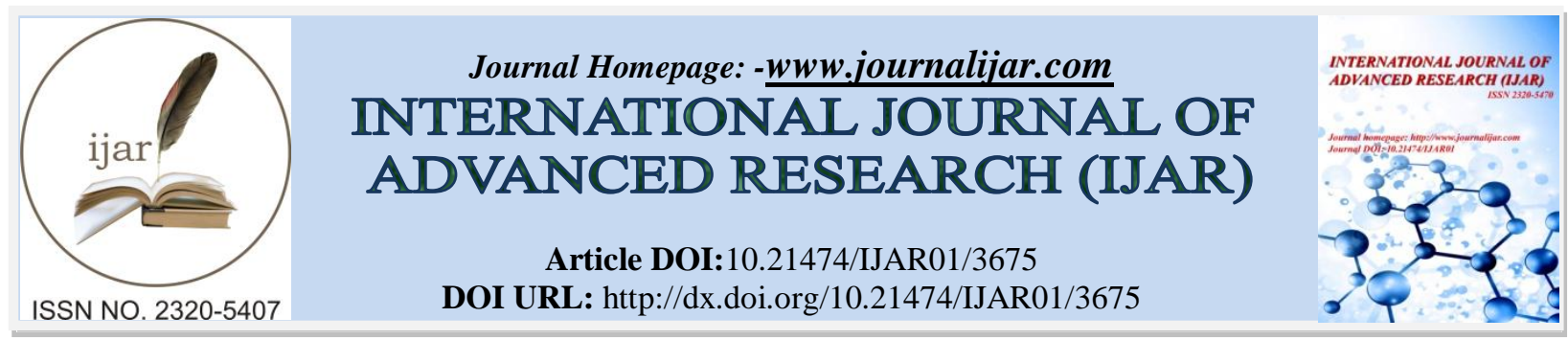

RESEARCH ARTICLE

\title{
THREE PHASE FOUR WIRE UNIFIED POWER QUALITY CONDITIONER FOR POWER QUALITY IMPROVEMENT
}

Nandhini $M$ and Indhumathi $M$.

B.E- Final Year Students.

\section{Manuscript Info}

Manuscript History

Received: 12 January 2017

Final Accepted: 02 February 2017

Published: March 2017

Key words:-

UPQC, APF, series APF, shunt APF,VSI

\section{Abstract}

This paper presents a novel structure for a three phase four-wire (3P4W) distribution system utilizing unified power quality conditioner (UPQC). The 3P4W system is realized from a three-phase three-wire system where the neutral of series transformer used in series part UPQC is considered as the fourth wire for the $3 \mathrm{P} 4 \mathrm{~W}$ system. A new control strategy to balance the unbalanced load currents is also presented in this paper. The neutral current that may flow toward transformer neutral point is compensated by using a four-leg voltage source inverter topology for shunt part. Thus, the series transformer neutral will be at virtual zero potential during all operating conditions. The simulation results based on MATLAB/Simulink are presented to show the effectiveness of the proposed UPQC-based 3P4W distribution system. Index Terms- Active power filter (APF), four-leg voltagesource inverter (VSI) structure, three-phase four-wire $(3 \mathrm{P} 4 \mathrm{~W})$ system, unified power quality conditioner (UPQC).

Copy Right, IJAR, 2017,. All rights reserved.

\section{Introduction:-}

The use of sophisticated equipment/loads at transmission and distribution level has increased considerably in recent years due to the development in the semiconductor device technology. The equipment needs clean power in order to function properly. At the same time, the switching operation of these devices generates current harmonics resulting in a polluted distribution system. The power-electronics-based devices have been used to overcome the major power quality problems. To provide a balance, distortion-free, and constant magnitude power to sensitive load and, at the same time, to restrict the harmonic, unbalance, and reactive power demanded by the load and hence to make the overall power distribution system more healthy, the unified power quality conditioner (UPQC) is one of the best solutions .A three-phase four-wire $(3 \mathrm{P} 4 \mathrm{~W})$ distribution system can be realized by providing the neutral conductor along with the three power lines from generation station or by utilizing a delta-star $(\Delta-\mathrm{Y})$ transformer at distribution level. The UPQC installed for 3P4W application generally considers 3P4W supply .This paper proposes a new topology/structure that can be realized in UPQC-based applications, in which the series transformer neutral used for series inverter can be used to realize a 3P4W system even if the power supplied by utility is three phase three-wire $(3 \mathrm{P} 3 \mathrm{~W})$. This new functionality using UPQC could be useful in future UPQC-based distribution systems. The unbalanced load currents are very common and yet an important problem in 3P4W distribution system. This paper deals with the unbalanced load current problem with a new control approach, in which the fundamental active powers demanded by each phase are computed first, and these active powers are then redistributed equally on each of the phases. Thus, the proposed control strategy makes the unbalanced load currents as perfectly balanced source currents using UPQC. The proposed 3P4W distribution system realized from existing 3P3W UPQC-based system 


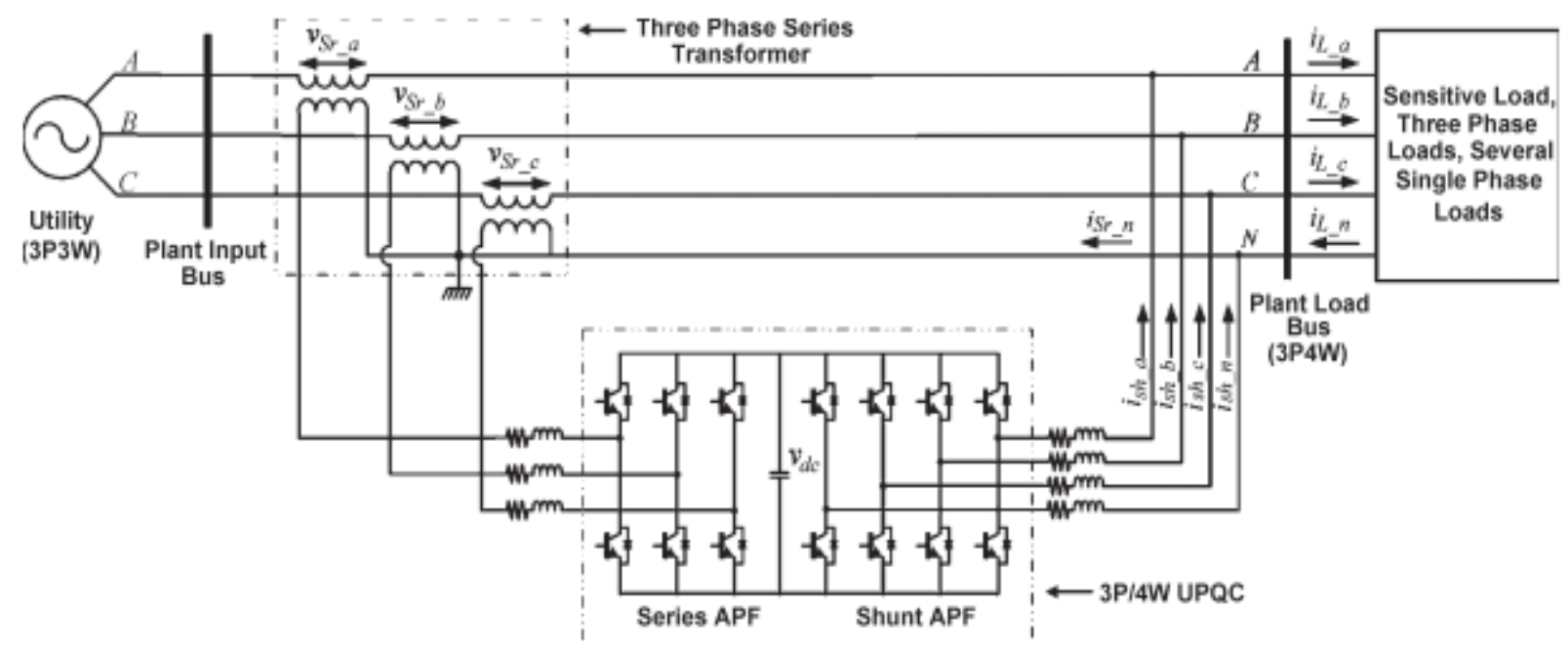

Fig:-Proposed 3P4W system realized from a 3P3W system utilizing UPQC.

Proposed 3p4w Distribution System Utilizing Upqc:-

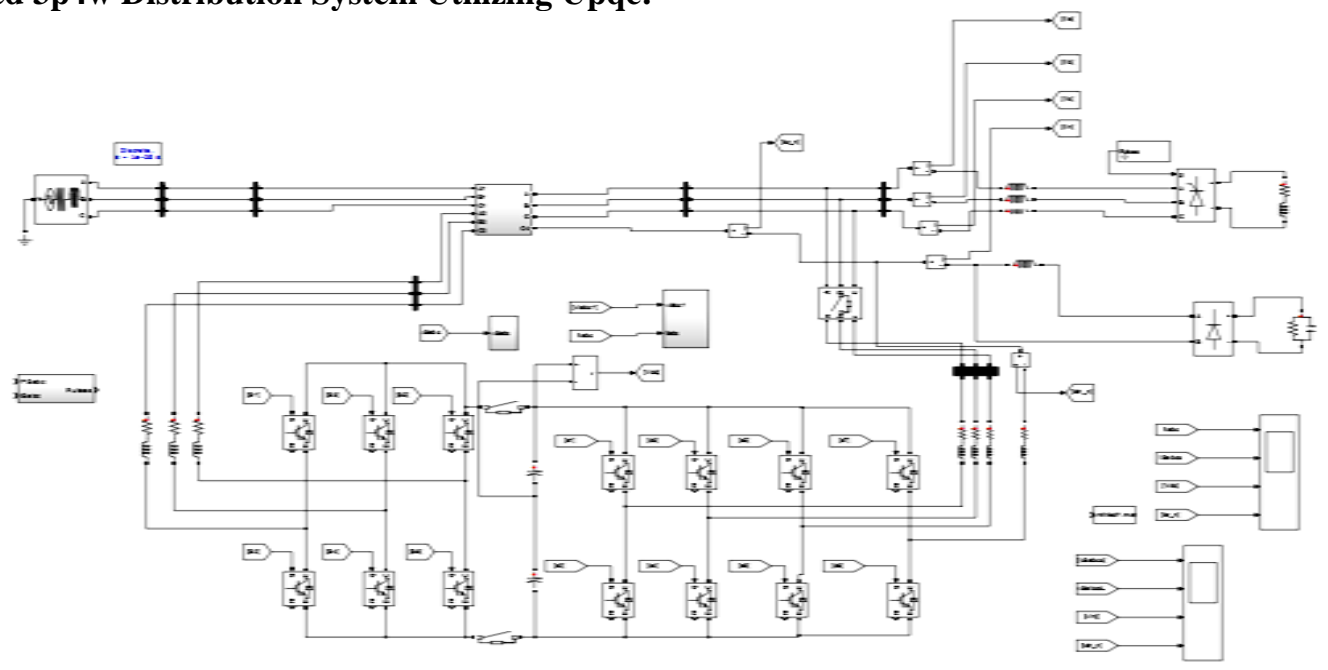

Figure: - Simulation Block Diagram of 3P4W system realized from a 3P3W system utilizing UPQC.

Generally, a 3P4W distribution system is realized by providing a neutral conductor along with three power conductors from generation station or by utilizing a three-phase $\Delta-\mathrm{Y}$ transformer at distribution level shows a $3 \mathrm{P} 4 \mathrm{~W}$ network in which neutral Conductor is provided from the generating station it shows a 3P4W distribution network considering a $\Delta-\mathrm{Y}$ transformer. Assume a plant site where three-phase three-wire UPQC is already installed to protect a sensitive load and to restrict any entry of distortion from load side toward utility

If we want to upgrade the system now from $3 \mathrm{P} 3 \mathrm{~W}$ to $3 \mathrm{P} 4 \mathrm{~W}$ due to installation of some single-phase loads and if the distribution transformer is close to the plant under consideration, utility would provide the neutral conductor from this transformer without major cost involvement. In certain cases, this may be a costly solution because the distribution transformer may not be situated in close vicinity. Recently, the utility service providers are putting more and more restrictions on current total harmonic distortion (THD) limits, drawn by nonlinear loads, to control the power distribution system harmonic pollution. At the same time, the use of sophisticated equipment/load has increased significantly, and it needs clean power for its proper operation. Therefore, in future distribution systems and the plant/load centers, application of UPQC would be common. It shows the proposed novel 3P4W topology that can be realized from a 3P3W system. This proposed system has all the advantages of general UPQC, in addition to easy expansion of $3 \mathrm{P} 3 \mathrm{~W}$ system to $3 \mathrm{P} 4 \mathrm{~W}$ system. Thus, the proposed topology may play an important role in the 
future 3P4W distribution system for more advanced UPQC based plant/load center installation, where utilities would be having an additional option to realize a 3P4W system just by providing a 3P3W supply. The UPQC should necessarily consist of three-phase series transformer in order to connect one of the inverters in the series with the line to function as a controlled voltage source.

If we could use the neutral of three-phase series transformer to connect a neutral wire to realize the $3 \mathrm{P} 4 \mathrm{~W}$ system, then 3P4W system can easily be achieved from a 3P3W system .The neutral current, present if any, would flow through this fourth wire toward transformer neutral point. This neutral current can be compensated by using a split capacitor topology [2], [9], [10] or a four-leg voltage-source inverter (VSI) topology for a shunt inverter [2], [11]. The four-leg VSI topology requires one additional leg as compared to the split capacitor topology. The neutral current compensation in the four-leg VSI structure is much easier than that of the split capacitor because the split capacitor topology essentially needs two capacitors and an extra control loop to maintain a zero voltage error difference between both the capacitor voltages, resulting in a more complex control loop to maintain the dc bus voltage at constant level. In this paper, the four-leg VSI topology is considered to compensate the neutralcurrent flowing towards the transformer neutral point.A fourth leg is added o the existing 3P3W UPQC, such that the transformer neutral point will be at virtual zero potential.Thus the proposed structure would help to realize a $3 \mathrm{P} 4 \mathrm{~W}$ system from a 3P3W system at distribution load end.

\section{Simulation Block Diagrams and Results:-}

The simulation results for the proposed 3P4W system realized from a 3P3W system utilizing UPQC.

Utility voltage are assumed to be distorted with voltage THD of $35.41 \%$. The resulting load current profile has THD of $12.1 \%$. The UPQC should maintain the voltage at the load bus at a desired value and free from distortion. The plant load is a assumed to be the combination of a balanced three phase diode bridge rectifier followed by an RL load, which act as a harmonic generating load and three different single. This would eventually result in easy expansion from 3P3W to3P4W systems. A control strategy to generate balanced reference source current under unbalanced load condition is also proposed in this paper.

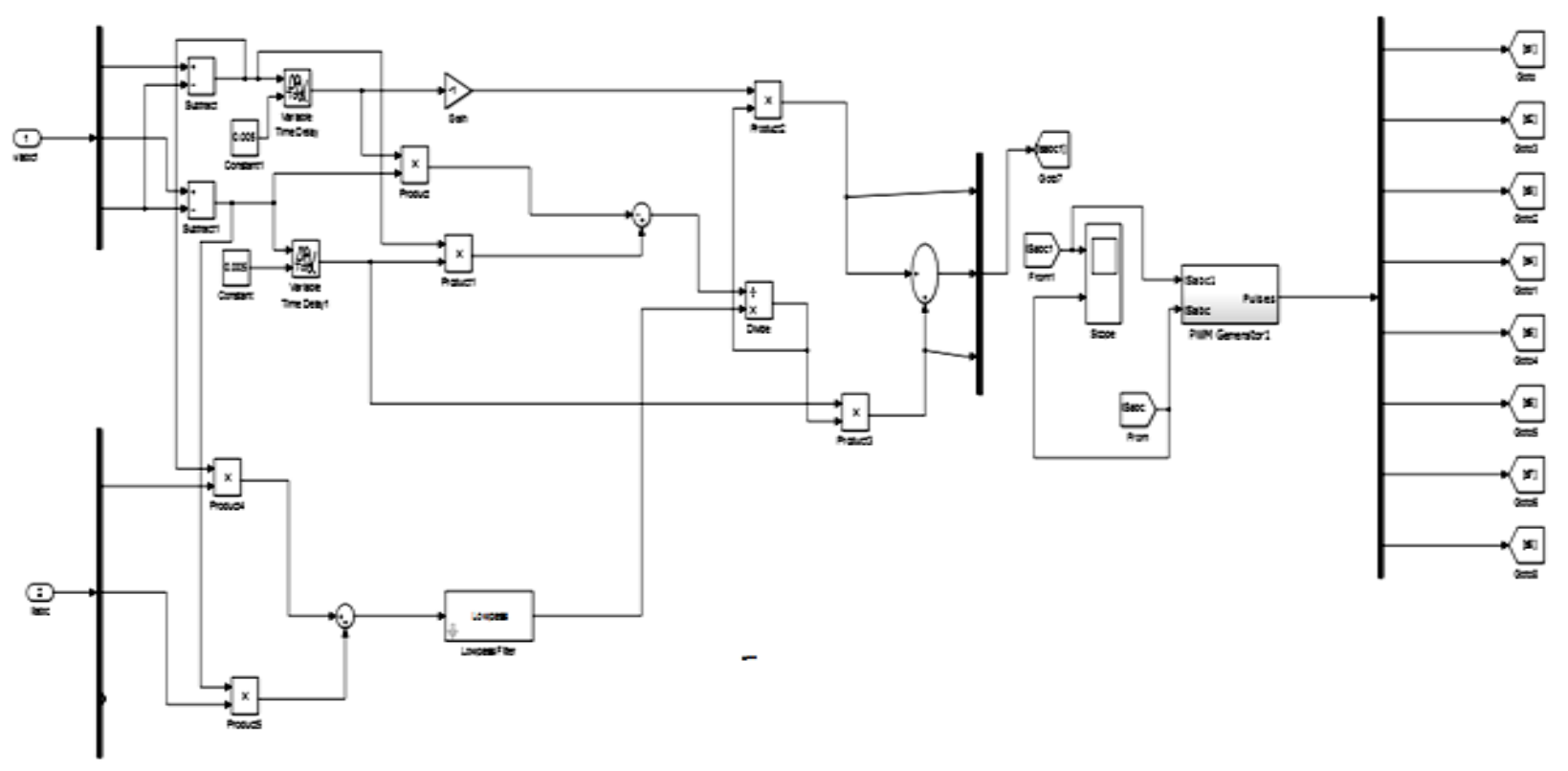

Fig: - Shunt Active Power Filter. 


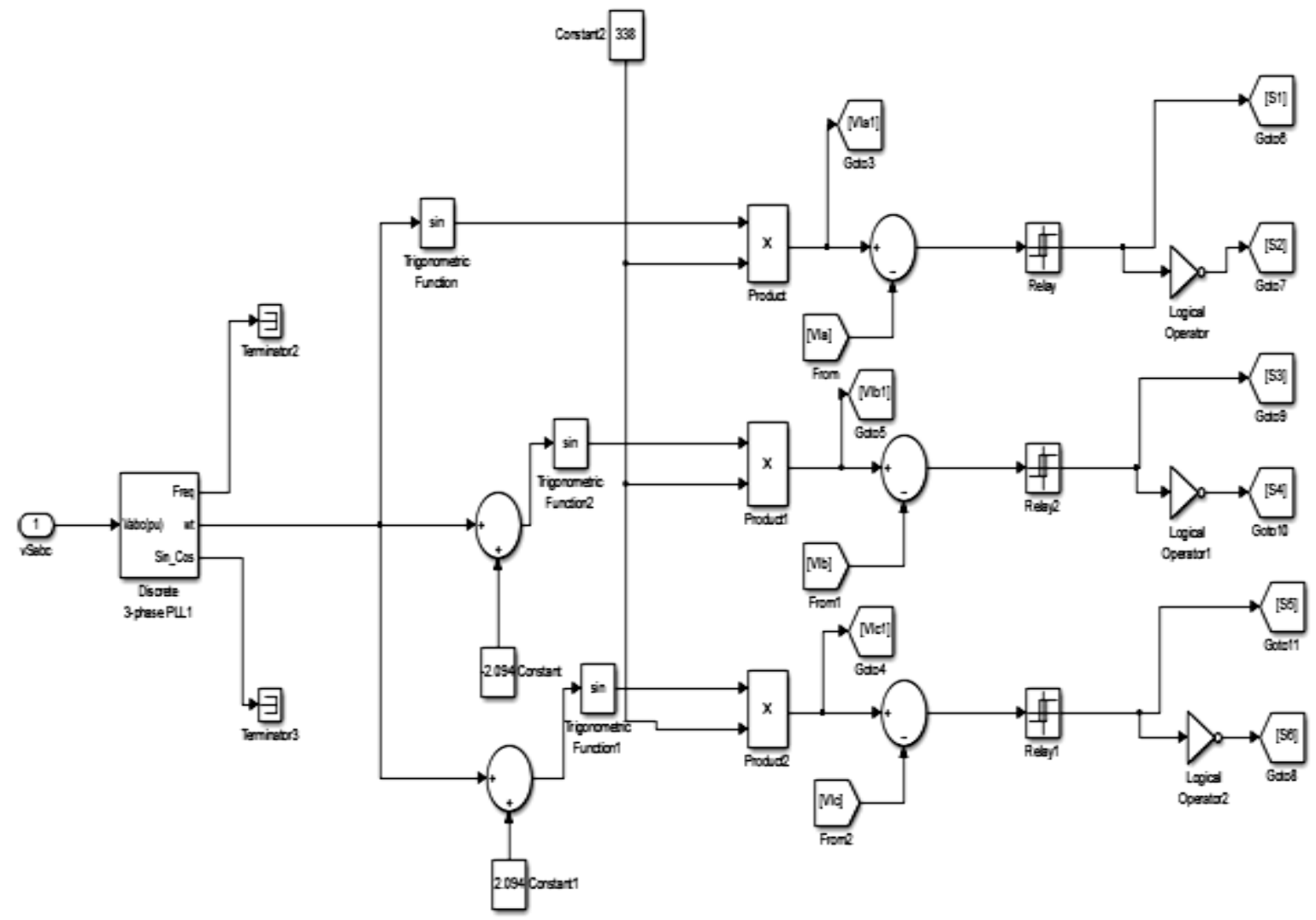

Figure: - Series Active Power Filter

The series active power filter injects the required compensating voltages through series transformer, making the load voltage free from distortion (THD $=1.51 \%$ ) and at a desired level in load voltage. The series active power filter injected voltage profile

The compensated source currents are perfectly balanced with the THD of $2.26 \%$.The compensating current injected through the fourth leg of the shunt APF. The load neutral current profile, the shunt APF effectively compensates the current flowing toward the transformer neutral point. Thus, the series transformer neutral point is maintained at virtual zero potential Simulation Block Diagram of 3P4W system realized from a 3P3W system utilizing UPQC. 


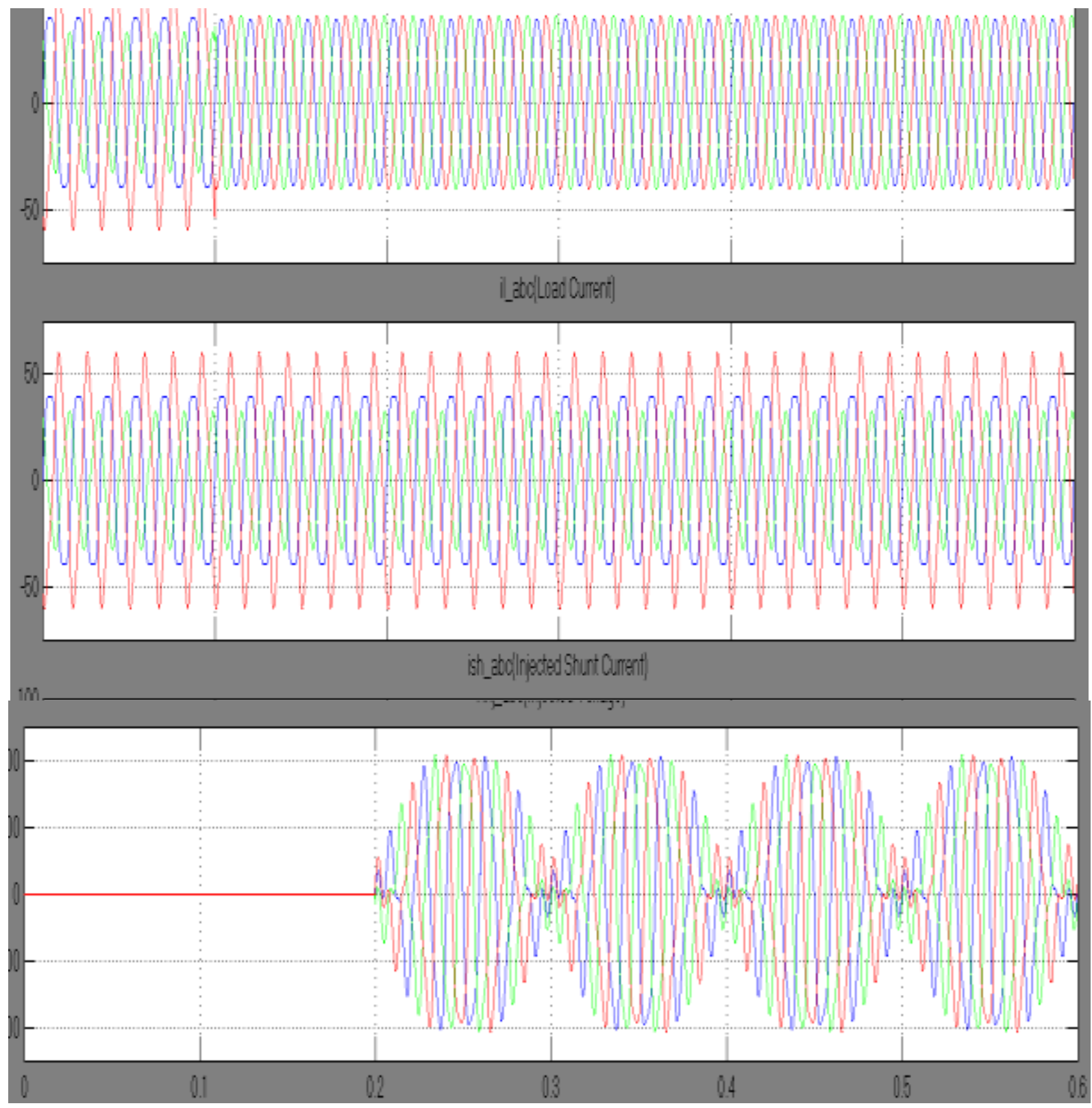

\section{Conclusion:-}

The design of a unified power quality conditioner (UPQC) connected to 3P4W distribution system has been presented in this project. Where UPQC is installed to compensate the different power quality problems, which may play an important role in future UPQC- based distribution system. The simulation results shows that the distorted and unbalanced load currents seen from the utility side act as perfectly balanced source currents and are free from distortion. Here we can absorb the power quality problems like voltage and current unbalanced and reduced the total harmonic distortion (THD) of 3P4W system utilizing 3P3W system to connect the UPQC. The neutral current that may flow toward the transformer neutral point is effectively compensated such that the transformer neutral point is always at virtual zero potential.

\section{Scope for Future Work:-}

Proposed model for the UPQC is to compensate input voltage harmonics and current harmonics caused by nonlinear load. The work can be extended to compensate the supply voltage and load current imperfections such as sags, swells, interruptions, voltage imbalance, flicker, and current unbalance. Proposed UPQC can be implemented using Multi converter-unified power quality conditioning system (MC-UPQC). 


\section{References:-}

1. Vinodkhadkikar, Ambrish Chandra, "A novel structure for three-phase four-wire distribution system utilizing unified power quality conditioner(UPQC)," IEEE Transaction on industry application, Vol.45,no.5,pp.18971902,Sep/oct.2009.

2. B. Singh, K. Al-Haddad, and A. Chandra, "A review of active power filters for power quality improvement," IEEE Trans. Ind. Electron., vol. 45, no. 5, pp. 960-971, Oct. 1999.

3. Y.Komatsu and T.Kawabata, "A Control method of active power filter in unsymmetrical and distorted voltage system," in proc.Conf.IEEE Power Convers. 1997, vol.1, pp.161-168.

4. C. A. Quinn and N. Mohan, "Active filtering of harmonic currents in three-phase, four- wire systems with threephase and single-phase nonlinear loads," in Proc. 7th IEEE APEC, 1992, pp. 829-836.

5. M.Aredes, K.Heumann, and E.h.Watanabe, "A universal active power line conditioner," IEEE Trans. power Del., vol.13, no.2, pp.542-551, Apri.1998.

6. R. Fernanda and I. Valade, "UPQC compensation strategy and design aimed at reducing losses," in Proc. IEEE ISIE, 2002, vol. 4, pp. 1264-1270.

7. G. Chen, Y. Chen, and K. M. Smedley, "Three-phase four-leg active power quality conditioner without references calculation," in Proc. 19th IEEEAPEC, 2004, vol. 1, pp. 829-836. 